\title{
Gamificação em saúde bucal: experiência com escolares de zona rural
}

Márcia Cançado Figueiredo*; Mariana Garcia**; Dante Augusto Couto Barone***, Roberta Oliveira****; Guilherme Lurmmerz**

* Professora da Faculdade de Odontologia, Departamento de Cirurgia e Ortopedia, UFRGS.

** Estudante da Faculdade de Odontologia da UFRGS.

*** Professor do Instituto de Informática da UFRGS.

**** Estudante do Instituto de Informática da UFRGS.

\section{RESUMO}

A utilização do brincar como estratégia adicional ao aprendizado pode trazer benefícios tanto às crianças quanto aos seus responsáveis e profissionais de saúde, que poderão lançar mão de um recurso inovador para a conquista de seus objetivos. Neste trabalho objetivou-se avaliar a percepção de escolares da zona rural sobre a utilização de um software educativo com temática relacionada à higiene bucal. $\mathrm{O}$ software "Dentino" foi utilizado por quarenta e cinco crianças em uma escola da zona rural do estado do Rio Grande do Sul, obtendo altos índices de aceitação. Após jogarem, todos os escolares afirmaram sentir-se motivados a cuidar de seus dentes. A aplicação do "Dentino" recebeu uma resposta bastante satisfatória, proporcionando momentos de lazer e entrosamento entre os estudantes, e atuando como ferramenta de ensino e motivação para os cuidados em saúde bucal.

Descritores: Saúde Bucal. Software. Educação em Odontologia

\section{INTRODUÇÃ̃O}

Atualmente, a computação doméstica e o uso do computador como ferramenta de apoio ao ensino são realidades. Os softwares educativos e os jogos eletrônicos proporcionam ao aluno, além de diversão, a expansão de habilidades que permitem o desenvolvimento das inteligências múltiplas. Segundo Oliveira, Matheus e Bergamaschi ${ }^{1}$ muitos professores reclamam que não conseguem manter a atenção dos alunos e que os mesmos não demonstram interesse pelos assuntos ensinados em sala de aula. Não se pode negar que essa nova geração está muito mais ligada à tecnologia do que as gerações passadas. Faz-se necessário, então, o uso de novas metodologias de ensino que prendam a atenção do aluno para que o mesmo tenha vontade de aprender cada vez mais. Com isso, entram em cena os jogos eletrônicos educativos, que apresentam a possibilidade de visualização na prática o que as crianças aprendem na teoria. Simplesmente jogando, elas aprendem de maneira inconsciente ${ }^{1}$.

As vantagens do uso da informática educativa são evidentes no cotidiano dos profissionais da educação, pois a criança está diante do diferente, lúdico, instigante e atrativo; da resposta imediata; dos resultados interessantes; da flexibilidade do pensamento; do desenvolvimento do raciocínio lógico; do foco de atenção e concentração, assim como da expressão emocional. Em consequência, os alunos desenvolvem potencialidades e habilidades antes não reveladas, aguçando a 
definição das inteligências múltiplas. ${ }^{2}$

Antunes $^{3}$ acredita que a eficácia dos softwares educativos se deve à combinação de diferentes linguagens e da multimídia, com interatividade e criatividade, típicas dos ambientes digitais. Esses se apresentam como uma ferramenta pedagógica auxiliar, propondo uma maneira diferente de ensinar e levando o escolar a aprender de forma divertida. Tais ferramentas permitem uma interação com o conteúdo, proporcionando ao jogador autonomia no aprender. Os softwares educativos constroem a vontade de jogar, estimulando o aluno a pensar e a tomar decisões a partir do momento que simula problemas e situações virtuais.

De acordo com Lascalla ${ }^{4}$, devido à constante evolução dos conceitos de promoção de saúde, o entendimento epidemiológico de multifatoriedade e a proposta de tratamento segundo o risco, a prática odontológica voltouse para a promoção de saúde, enfatizando-se a necessidade de atuação nos agentes predisponentes ou causadores das doenças e não somente no tratamento cirúrgicorestaurador.

Uma das principais abordagens odontológicas na educação em saúde visa melhorar a eficiência da higiene bucal realizada pelo próprio indivíduo, porque é a única medida racional de longo prazo para o controle mecânico da placa bacteriana. Sheiham, Maizels e Cushing ${ }^{5}$ destacaram que há muita necessidade de programas eficazes de educação em saúde bucal, seja no âmbito público ou no privado. Para Biscoli ${ }^{6}$, a utilização do brincar como uma estratégia extra ao aprendizado está apta a trazer benefícios tanto às crianças, que terão mais condições facilitadoras para a aprendizagem, quanto aos seus responsáveis e profissionais de saúde, que poderão lançar mão de um recurso adicional para a conquista de seus objetivos.

Diante deste contexto, este trabalho objetivou avaliar a percepção de escolares na faixa etária de 06 a 14 anos de idade, quanto à utilização de um software educativo com temática relacionada à higiene bucal, durante uma atividade extensionista interdisciplinar em saúde, realizada em uma escola de ensino fundamental em zona rural do estado do Rio Grande do Sul.

\section{REVISÃO DE LITERATURA}

Brincar é uma atividade predominante da infância e vem sendo explorada no campo científico com o intuito de caracterizar as suas peculiaridades, identificar as suas relações com o desenvolvimento e com a saúde e, entre outros objetivos, intervir nos processos de educação e de aprendizagem das crianças. Existe uma linha muito tênue que diferencia a brincadeira do jogo. Pesquisadores como Friedmann $^{7}$, Biscoli ${ }^{6}$ e Vygotsky $^{8}$ não fazem diferenciação semântica entre jogar e brincar. Estes autores utilizam ambas as palavras para designar o mesmo comportamento, a atividade lúdica, e acrescentam que o termo jogo vem do latim iocus, que significa diversão, brincadeira.

Brougère e Wajskop ${ }^{9}$ e Brougère ${ }^{10}$ afirmam que a brincadeira é simbólica e o jogo funcional, ou seja, enquanto a brincadeira tem a característica de ser livre e ter um fim em si mesma, o jogo inclui a presença de um objetivo final a ser alcançado, a vitória. Este objetivo final pressupõe o aparecimento de regras préestabelecidas. Estas regras geralmente já chegam prontas às mãos da criança. As regras dos jogos têm relação íntima com as regras sociais, morais e culturais existentes. $\mathrm{O}$ jogo de xadrez é um exemplo disso, uma vez que, quanto maior o grau de poder da peça, maiores são as possibilidades de ações junto ao jogo.

Para Brougère ${ }^{10}$, mesmo as regras chegando prontas às crianças, estas têm a liberdade e a flexibilidade de aceitá-las, modificá-las ou simplesmente ignorá-las. Isto pode depender do contexto no qual a criança 
estará inserida e dos parceiros dos jogos. O objetivo final de uma criança perante um jogo é a vitória sobre o oponente, entretanto, mesmo que a criança não vença, o prazer usufruído durante o jogo pode fazer com que a criança retorne a jogar. Portanto, o prazer do jogo pelo jogo faz com que esta atividade tenha um fim em si mesma, não importando mais a vitória final, mas sim o processo. Estas características, de flexibilidade, de prazer e de fim em si mesmo, fazem com que o jogar se confunda com o brincar. O brincar e o jogar passam a ser indistintos e, isto facilita para quem quer ensinar através do jogar.

De acordo com Vincentini ${ }^{11}$, o mundo atual encontra-se em constante transformação e, em consequência, as inovações tecnológicas se expandem. Em decorrência destas transformações, a tecnologia adentrou em diversos campos da sociedade. A escola não pode se excluir desse fenômeno, ao contrário, deve se adaptar à atual realidade tecnológica e explorar esses recursos utilizando-os no processo de ensino-aprendizagem.

Os jogos eletrônicos são fenômenos de uma cultura digital, sendo utilizados das mais variadas formas e finalidades, como no treinamento de habilidades motoras e como artefato de entretenimento. A introdução desse recurso no meio escolar deve ser analisada, estudada e testada, para que não seja desperdiçado e possa enriquecer o processo ensino/aprendizagem. Todavia, assim como enfoca Antunes3: "todo jogo pode ser usado para muitas crianças, mas seu efeito sobre a inteligência será sempre pessoal e impossível de ser generalizado". Os jogos ajudam no estímulo da criança e são o alimento das inteligências, pois "o estímulo não atua diretamente sobre uma janela, mas se aplicado adequadamente desenvolve habilidades, e estas sim, conduzem às aprendizagens significativas". O autor afirma, ainda, que devese optar por jogos que possam ser trabalhados de uma forma contínua, e salienta a necessidade de pesquisa sobre os temas abordados nos softwares educativos antes de escolhê-los.

Segundo Moita ${ }^{12}$, cresce a cada dia o número de jovens que fazem uso da Internet e jogos eletrônicos como forma de lazer. Enquanto essa modernidade ocorre na sociedade, as escolas com ensino tradicional enfrentam diversos problemas, pois não dispõem de professores qualificados $\mathrm{e}$ preparados para a era da informática, tendo, como consequência, alunos desinteressados e descompromissados com a aprendizagem em sala de aula. Para Ramos ${ }^{13}$, torna-se necessário que a escola reveja seu papel e que inicie um processo de adequação às novas tecnologias, pois estas fazem parte da vida de sua clientela. A eficácia dos softwares educativos se deve à combinação de diferentes linguagens e da multimídia, com interatividade e criatividade, típicas dos ambientes digitais.

Os softwares educativos permitem uma interação com o conteúdo, proporcionando ao jogador autonomia no aprender, assim como salienta Moita ${ }^{12}$ : "ser autônomo é poder elaborar suas próprias leis, compreender as conexões que se realizam no interior do seu próprio pensamento. Ser autônomo é ser aluno do paraíso". Os softwares educativos constroem a vontade de jogar, estimulando o aluno a pensar e a tomar decisões a partir do momento que simula problemas e situações virtuais.

Ramos $^{13}$ afirma que Jogos eletrônicos são um dos meios mais propícios à construção do conhecimento e, como ferramentas educacionais, quando empregados em ambientes educacionais formais, podem ser mais um instrumento de ensino. Para exercê-lo a criança utiliza seu equipamento sensóriomotor, pois o corpo é acionado e o pensamento também, e enquanto é desafiada a desenvolver habilidades operatórias que envolvam a identificação, observação, comparação, análise, 
síntese e generalização, ela vai conhecendo suas possibilidades e desenvolvendo cada vez mais a autoconfiança. É fundamental, no jogo eletrônico, que a criança descubra por si mesma, e para tanto o professor deverá oferecer situações desafiadoras que motivem diferentes respostas, estimulando a criatividade e a redescoberta.

Cordazzo e Vieira ${ }^{14}$ relataram que o aluno, ao experimentar a sensação de liberdade no ato de aprender, sente-se motivado e, quando possui computador em casa, certamente irá explorar melhor o jogo por conta própria, de uma maneira individual e autônoma. O software educativo pode ajudar o aluno a descobrir acontecimentos reais, mesmo que ainda não tenham sido vivenciados por ele. Com as experiências virtuais ele pode se imaginar em tal situação na realidade, estabelecendo relações entre os conhecimentos adquiridos durante o jogo e os acontecimentos da sua vida cotidiana, auxiliando na formação de valores sociais e construindo a noção de cidadania.

Para Alves ${ }^{2}$, esta parceria entre educação e tecnologia é muito difícil de ser efetivada no que se refere às tecnologias digitais, principalmente, porque os professores têm dificuldades de interação. Eles já admitem utilizar o computador e a internet para preparar as suas aulas, mas não conseguem ainda utilizálos nas suas atividades em sala de aula com seus estudantes, como instrumento pedagógico. A partir do momento que os professores conhecerem as novas tecnologias de comunicação e informação (TICs) através do uso do computador ou tablet ou até mesmo do aparelho celular, eles percebem que existem recursos práticos que podem tornar a sua aula mais atrativa e prazerosa. Carvalho, Alves e Gomes ${ }^{15}$ verificaram que o universo dos jogos eletrônicos é um ambiente que precisa ser mais familiar aos educadores, pois se aproximar desse universo é também se aproximar dos alunos. Torna-se, assim, de grande importância que os professores e a escola se aproximem dessas novas formas de aprender, dessas novas ferramentas de aprendizagem que estão surgindo na sociedade atual.

De acordo com Bittencourt ${ }^{16}$ os softwares educacionais vêm entrando no mercado mundial de forma muito acelerada. Inúmeros países como Inglaterra, França e Estados Unidos, dentre outros, desenvolveram projetos de uso do microcomputador em educação e, consequentemente, desenvolveram produtos de software específicos para sanar suas necessidades. $\mathrm{O}$ mesmo tem ocorrido no Brasil, onde diversos projetos de pesquisa relacionados ao desenvolvimento de softwares para os mais diversos conteúdos programáticos vêm sendo desenvolvidos. Os softwares oportunizam uma maior interação entre o aluno, o professor e o ambiente de aprendizagem. Porém nem todos os que encontramos no mercado oferecem qualidade. Há softwares cujos resultados são bastante óbvios. São tão predefinidos que o aluno não possui alternativa senão a de seguir um único caminho para atingir o resultado esperado.

Segundo $\operatorname{Cox}^{17}$, o sucesso de um software depende não apenas da forma como foi concebido, mas principalmente do modo de utilização do mesmo pelo professor, pois o primordial é fazer com o que o aluno tenha prazer em construir seu próprio conhecimento. Costa e Monteiro ${ }^{18}$ complementam, afirmando que o que importa não é qual a tecnologia está disponível para o aluno, e sim como ela é utilizada. O valor das TICs na educação é derivado inteiramente de sua aplicação.

O jogo garante, pela sua natureza, o desenvolvimento de habilidades cognitivas e motoras, além de trabalhar a dimensão da autoconfiança e motivação, intrínseca para os envolvidos no processo de ensino/aprendizagem em quaisquer áreas do conhecimento $^{12}$. Os jogos eletrônicos também 
são importantes no desenvolvimento do aluno, porém não têm a mesma importância do software educativo, pois estes além de serem jogos, que desenvolvem a competência lógica, também trabalham auxiliando os conteúdos curriculares em sala de aula, tornando-se peça fundamental em dias atuais na aprendizagem do aluno $^{12,13,18}$.

Segundo o texto "Jogos ajudam a desenvolver habilidades" do Jornal Contexto ${ }^{19}$, os jogos são fundamentais e as empresas estão fazendo uso de tal recurso para capacitação de seus funcionários. Hoje em dia, "ser bom" no videogame pode ainda garantir um bom trabalho aos jovens. Se você acha exagero, saiba que cada vez mais as empresas contratam funcionários levando em conta sua capacidade em tomar decisões rápidas e, o mais importante, corretas. Quem é "fera" nos games tem conseguido vantagens na hora de procurar emprego. Os softwares educativos ensinam aos alunos normas, regras, somas, multiplicação, divisão, subtração, cartas, química, testes, coordenação motora, mapas, solo, vegetação, português, ciências, aritmética, frações, geografia, língua inglesa e saúde. Assim sendo, pode-se encontrar nos jogos subsídios para trabalhar quase qualquer conteúdo curricular, basta apenas o professor se adequar a esse mundo fascinante. $\mathrm{O}$ contato com o computador auxilia também na memorização do aluno, pois ao jogar necessita-se de certa habilidade para pressionar com eficiência e rapidez as diversas teclas do computador.

A ideia de o ensino despertar o interesse do aprendiz gerou outro entendimento sobre material pedagógico; o profissional que ensina passou a ser estimulador, de uma maneira eficaz. Nesse contexto, o jogo passa a ser uma ferramenta ideal da aprendizagem, no sentido de que gera estímulo ao aprendiz. O conceito de educação em saúde também vai além da transmissão de informações, configurando combinações de experiências de aprendizagem delineadas com vistas a facilitar ações voluntárias conducentes à saúde. Essas combinações envolvem troca de experiências de vida, aspectos comportamentais, medidas terapêuticas e interacionais. Coscrato, Pina e Mello $^{20}$ concluíram que existem fortes evidências que determinam a eficácia de jogos de computador na educação em saúde de crianças e adolescentes, em relação à promoção de saúde (hábitos de higiene bucal e alimentares). Essas evidências são provenientes de estudos que avaliaram a aprendizagem e aspectos comportamentais após a utilização desses jogos.

\section{METODOLOGIA}

O software educativo utilizado nesse estudo é denominado "Dentino" e foi desenvolvido no Instituto de Informática pelos alunos do Programa de Educação Tutorial (PET Computação) da Universidade Federal do Rio Grande do Sul (UFRGS), através do programa Unity (Unity Technologies, São Francisco, EUA). É uma ferramenta de desenvolvimento de jogos que possui recursos avançados para a criação de títulos em 2D e 3D. Traz uma grande biblioteca de funcionalidades prontas para a realização de conexões em rede, geração de terrenos, criação de efeitos de iluminação e de personagens em 3D. A empresa apoia desenvolvedores independentes, fazendo com que cada jogo consiga chegar ao ponto mais alto de desenvolvimento ${ }^{21}$. O software "Dentino" é baseado na aventura do personagem principal, um dente molar, que atua contra bactérias e contra açúcares encontrados na alimentação, com o auxílio de escova, creme, fio dental e alimentos saudáveis, em ambiente que representa a cavidade bucal. Apresenta diversas fases, nas quais a higiene e a alimentação saudável são os recursos para ultrapassá-las, e no final do jogo conquista-se a saúde bucal (Figura 1). 


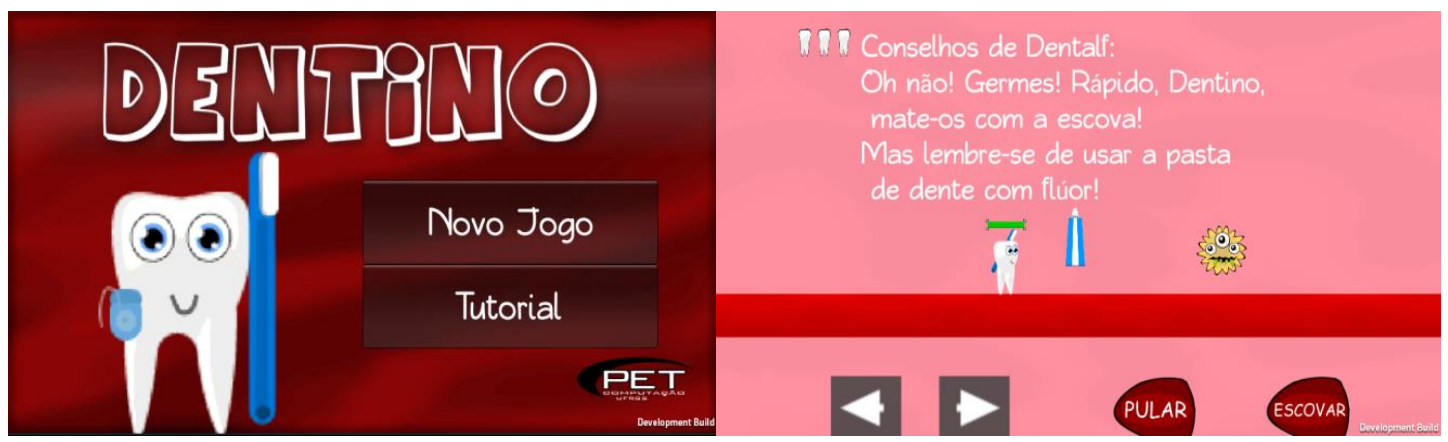

Figura 1 - Representação gráfica do Software "Dentino".

Este é um estudo de caráter quantitativo, desenvolvido com quarenta e cinco alunos de uma escola rural de Ensino Fundamental situada no município de General Câmara Santo Amaro, localizado a $94 \mathrm{Km}$ de distância da capital Porto Alegre, no estado do Rio Grande do Sul. Estes escolares eram participantes de uma ação de extensão interdisciplinar em educação em saúde, que têm por finalidade ampliar o acesso da população local, com alto índice de vulnerabilidade social, aos serviços de saúde.

O software "Dentino" foi disponibilizado aos alunos, com idades de 06 a 14 anos, sob supervisão de duas estudantes, dos cursos de Odontologia e Ciências da
Computação da UFRGS, no momento que antecedeu a escovação dental supervisionada (Figura 2). Após terminar de jogar, lhes foi oferecido um questionário contendo oito questões fechadas (Figura 3).

Todos os responsáveis pelos estudantes participantes da pesquisa assinaram um Termo de Consentimento Livre e Esclarecido, que lhes foi enviado previamente.

O estudo foi aprovado pelo Comitê de Ética em Pesquisa da Secretaria Municipal de Saúde de Porto Alegre sob o número 669 e os dados coletados foram analisados quantitativamente, com tabelamento em percentual, sendo apresentados em frequências relativa absoluta.
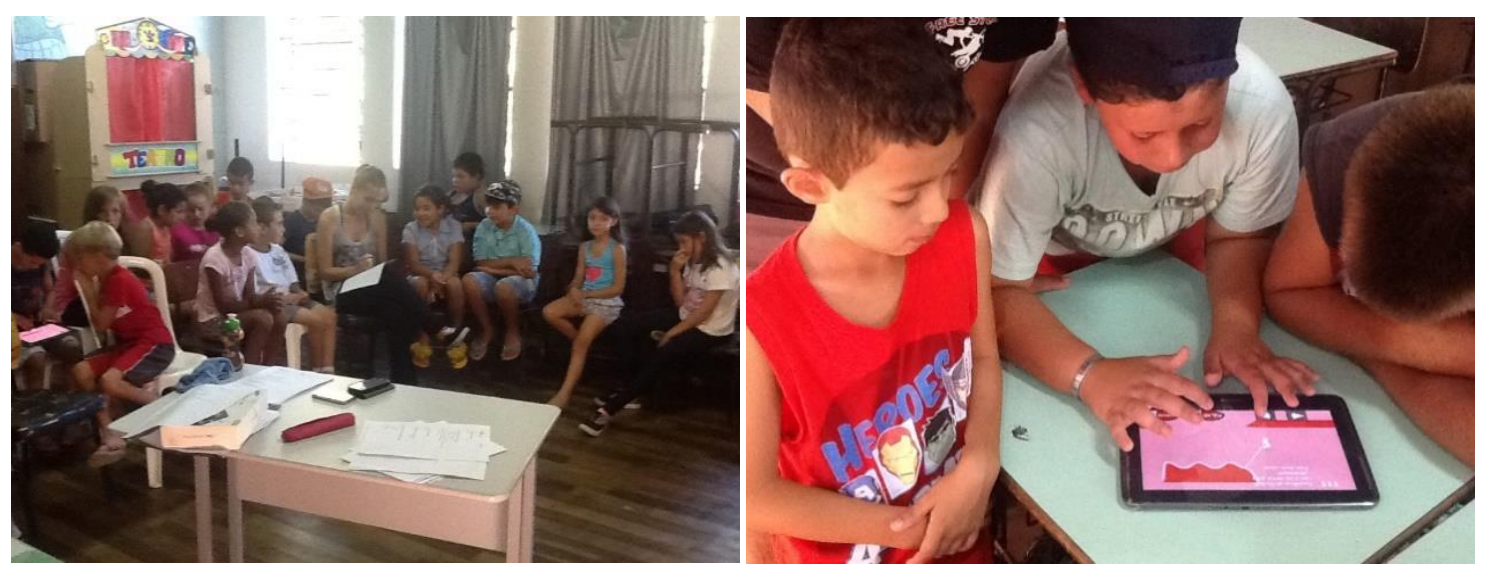

Figura 2 - Aplicação do software "Dentino" durante o mutirão de saúde na escola rural 
IDADE: SÉRIE:

1). Você gostou do jogo? ( ) SIM （） NÃO

2) O que você aprendeu com o jogo?

( ) Importância do uso do fio-dental

( ) Importância da escovação

( ) Importância do uso da pasta dental

( ) Comer doces muitas vezes ao dia é ruim para os dentes

( ) Escovar os dentes faz bem à saúde

( ) Não aprendi nada

3) O que achou do jogo? ( ) FÁCIL （ ) DIFÍCIL

4) Gostaria de jogar mais vezes? ( ) SIM （ ) NÃO

5) O que poderia ser melhorado no jogo?

( ) Cores

( ) Comandos

( ) Rapidez

( ) Músicas

( ) Personagens

( ) Estória

6). Você se sentiu motivado a cuidar de seus dentes? ( ) SIM （） NÃO

7). Qual sua nota para o jogo?
( ) 1
( ) 2
( ) 3
( $\begin{array}{ll}\text { ) } 4 & (\text { ) } 5\end{array}$

8). Qual sua nota para o que aprendeu com o jogo?
( ) 1
( ) 2
( ) 3
( ) 4
( ) 5

Figura 3 - Questionário respondido pelos estudantes.

\section{RESULTADOS}

Todas as crianças gostaram do software "Dentino" e 96,6\% relataram que ao jogá-lo aprenderam que escovar os dentes faz bem à saúde. Os percentuais de respostas a esta pergunta constam do Gráfico 1.

Com relação à pergunta: "O que poderia ser melhorado no jogo?" a resposta mis prevalente foi Rapidez (43,3\%) (Gráfico 2). O software "Dentino" foi considerado fácil de ser jogado por $86,6 \%$ dos escolares e apenas $13,3 \%$ o acharam difícil. Grande parte $(93,3 \%)$ dos estudantes gostariam de jogar mais vezes e 6,6\% não gostariam.

Após jogarem, todos os estudantes afirmaram sentir-se motivados a cuidar de seus dentes. Em uma escala de 1 a 5, 83,3\% deram nota 5 para o jogo, $10 \%$ atribuíram nota 4 e $6,6 \%$ nota 3 . 


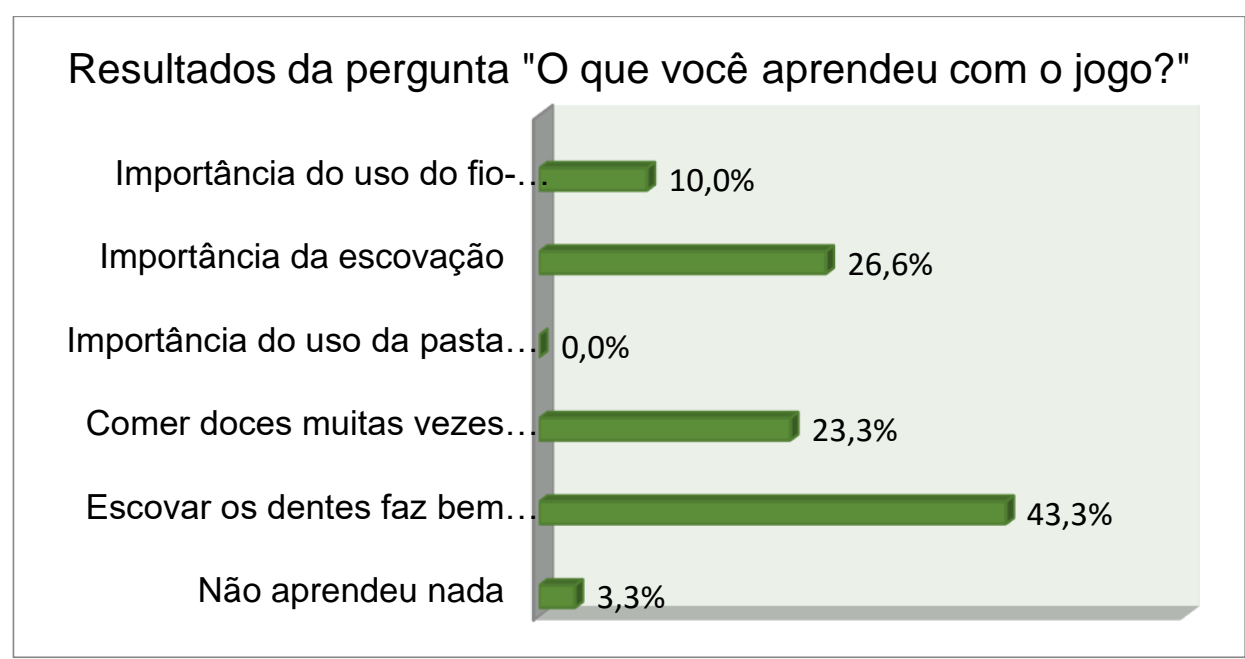

Gráfico 1 - Percentuais de respostas assinaladas pelos escolares à pergunta "O que você aprendeu com o jogo?"

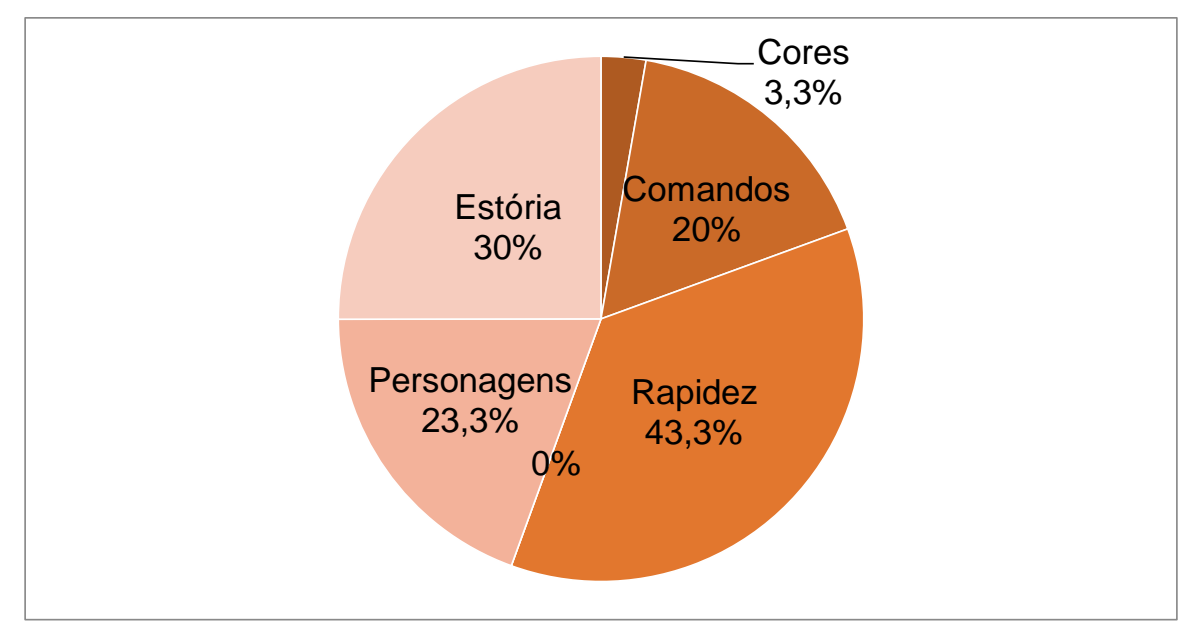

Gráfico 2 - Percentuais de respostas assinaladas pelos escolares à pergunta "O que poderia ser melhorado no jogo?"

\section{DISCUSSÃO}

Com o avanço tecnológico, o surgimento de novas TICs e, também, o crescimento do uso da rede mundial de computadores, a área da educação no Brasil e no mundo tem expandido seus horizontes no sentido de inserir tais tecnologias no meio acadêmico. A explosão das TICs se faz cada vez mais presente no dia a dia da população e ocasiona uma revolução tecnológica que está acarretando mudanças na sociedade com uma rapidez enorme ${ }^{22}$. Nesse sentido, se deve inserir novas TICs no processo educacional, com o intuito de ampliar ou desenvolver dinâmicas didáticas mais apropriadas em todos os setores e, deste modo, em educação em saúde.

Segundo o historiador francês Chartier ${ }^{23}$ em sua entrevista à Organização das Nações Unidas para a Educação, a Ciência e a Cultura (UNESCO), uma das maiores mudanças no mundo eletrônico é a possibilidade de associar ao texto músicas, sons, imagens e outros 
recursos, e também a capacidade inédita de agregar diferentes linguagens em um mesmo projeto. Diante desse cenário, a opção nesta investigação foi de utilizar o tablet, um computador pessoal, portátil, do tipo prancheta, para a aplicação de um software educativo em odontologia, caracterizando o uso da tecnologia de informação e comunicação no processo de ensino e aprendizagem para escolares de zona rural que, em sua maioria, nunca tivessem tido algum contato antes com elas.

Reategui e Moraes $^{24}$, utilizando softwares com agentes pedagógicos animados, desenvolvidos para auxiliar e motivar o ensino de conceitos básicos de determinado tema, recuperaram o interesse dos alunos que se mostraram mais entusiasmados e menos dispersivos. No presente estudo, o software educativo em odontologia "Dentino" foi responsável por possibilitar maior participação, autonomia e interação entre os alunos da escola rural e os acadêmicos da UFRGS, propiciando um ambiente coletivo favorável à construção do processo de ensino e aprendizagem em educação em saúde.

Em contrapartida, de acordo com Coscrato, Pina e Mello ${ }^{20}$, os jogos eletrônicos apresentam como desvantagens os problemas relacionados à usabilidade, em termos de qualidades variáveis dos locais que oferecem uso de computadores, e em termos de "alfabetização tecnológica", ou conhecimento e habilidades com computadores, sendo necessária a investigação rigorosa para avaliar as intervenções educativas e sua aplicabilidade para o público alvo. Considerando que o acesso pelos escolares da zona rural às TICs ainda é bastante reduzido, constatou-se durante a aplicação do "Dentino" que muitos deles nunca haviam manipulado um tablet, nem sequer sabiam da existência do mesmo e, grande parte não possuía habilidade para lidar com o dispositivo. Isto foi considerado uma limitação deste estudo, visto que a inserção de uma novidade na vida destes escolares da zona rural, pode por si só, ter sido o motivo da aprovação do software na totalidade dos casos.

Reforçando futuras pretensões, Marin et al. ${ }^{25}$ constataram que estudantes de zona rural que foram motivados e supervisionados por professores em sua higiene oral eram mais entusiasmados em manter sua saúde bucal do que aqueles que não obtiveram tal benefício. Portanto, a adoção de novas estratégias e a formação contínua, em um esforço multidisciplinar envolvendo cirurgiõesdentistas e professores do ensino fundamental, devem ser encorajadas. À vista disso observase o resultado deste estudo e, pode-se pensar em uma nova escola rural que forma cidadãos, sendo também um espaço de mudanças, de quebra de paradigmas, de inovação e, diante de tantas novidades, deve passar por transformações, sobretudo no tocante à inserção de novas tecnologias no que tange ao processo ensino-aprendizagem. Esta é a realidade: a educação atrelada à tecnologia.

As inovações advindas da inserção das tecnologias na educação ainda apresentam alguns desafios a serem transpostos, mas é inegável a contribuição dessas ferramentas no cotidiano dos jovens estudantes de áreas rurais. Assim, são notórios os benefícios e a efetividade do uso de softwares educativos em educação e promoção de saúde. Segundo Candeias $^{26}$, as intervenções lúdicas eficazes para a educação em saúde devem promover a aprendizagem evidenciada pelo aumento do nível de conhecimento, mudança de comportamentos e melhora na qualidade de vida das pessoas. $\mathrm{O}$ presente trabalho avaliou a aprendizagem e aspectos comportamentais somente após a intervenção, e encontrou resultados extremamente positivos. No entanto, considera-se que existe a necessidade de se avaliar a eficácia dessas intervenções lúdicas a médio e longo prazo, a fim de determinar se há retenção do conhecimento e se estas 
proporcionam mudanças comportamentais duradouras que terão impacto na qualidade de vida da população estudada. Novos estudos mais aprofundados e consistentes serão necessários, tendo em vista ser um assunto de extrema relevância, apesar de recente.

\section{CONCLUSÕES}

A aplicação do software "Dentino" para escolares da zona rural apresentou uma resposta bastante satisfatória, uma vez que os alunos gostaram do jogo e sentiram-se motivados aos cuidados com a sua própria saúde bucal;

Observou-se que o nível de atenção, e, por conseguinte, a obtenção de novos conhecimentos foi constatada em $96,6 \%$ dos estudantes e o interesse pelo assunto "escovação dentária" foi aumentado em 69,9\%;

Houve entrosamento dos escolares durante a aplicação do software "Dentino", proporcionando, além de aprendizagem, momentos de lazer e diversão para os estudantes.

\section{AGRADECIMENTOS}

Os autores agradecem aos acadêmicos do PET Computação da UFRGS, Cristiano Ruschel e João Paulo Ruschel, pelo apoio no desenvolvimento do software "Dentino".

\section{FOMENTO}

Edital PROEXT/SESU - Ministério da Educação

\section{REFERÊNCIAS}

1. Oliveira PR de, Matheus ML, Bergamaschi MP. Uso de jogos eletrônicos educativos para potencializar os processos de ensino e aprendizagem de matemática no ensino fundamental. Rev Ceciliana, 2013; 5(2):203-16.

2. Alves L. Tecnologia da Educação: A escola do amanhã. 2007. Disponível em: http://www.overmundo.com.br/overblog/e ducacao.
3. Antunes C. Jogos para a estimulação das múltiplas inteligências. Petrópolis, Rio de Janeiro: Vozes, 1998.

4. Lascala NT. Prevenção na Clínica Odontológica - Promoção de Saúde Bucal. São Paulo: Artes Médicas, 1997, p.95-99.

5. Sheiham A, Maizels JE, Cushing AM. The concept of need in dental care. Int Dent J 1982;32(2):265-70.

6. Biscoli IA. Atividade lúdica uma análise da produção acadêmica brasileira no período de 1995 a 2001. 2005. Dissertação de Mestrado, Programa de Pós-Graduação em Educação, Universidade Federal de Santa Catarina, Florianópolis.

7. Friedmann A. O direito de brincar: a brinquedoteca. $4^{a}$ ed. São Paulo: Abrinq, 1996.

8. Vygotsky LSA. Formação social da mente: o desenvolvimento dos processos psicológicos superiores. $4^{\mathrm{a}}$ ed. São Paulo: Martins Fontes, 1991

9. Brougère $G$, Wajskop $G$. Brinquedo e cultura. $2^{a}$ ed. São Paulo: Cortez, 1997.

10. Brougère G. Jogo e educação. Porto Alegre: Artes Médicas. 1998.

11. Vicentini C. Retos y promesas de la inclusión educativa en Venezuela. Venezuela: Ildis, 2006.

12. Moita F. Game on: jogos eletrônicos na escola e na vida da geração @. Campinas: São Paulo: Editora Alínea, 2007.

13. Ramos DK. A escola frente ao fenômeno dos jogos eletrônicos: aspectos morais e éticos. Novas Tecnologias na Educação 2008; 6 (1):1-10.

14. Cordazzo STD, Vieira M. Caracterização de brincadeiras de crianças em idade escolar. Psicologia: Reflexão e Crítica 2008; 21(3):365-73.

15. Carvalho AM, Alves MMF, Gomes PLD. Brincar e educação: concepções e possibilidades. Psicologia em Estudo 2005;10(2):217-26.

16. Bittencourt J. Informática na educação? Algumas considerações a partir de um exemplo. Rev Fac Educ 1998; 24(1):23-36.

17. Cox KK. Informática na educação escolar. Coleção polêmicas do nosso tempo, 87. 
Campinas, São Paulo: Autores Associados, 2003.

18. Costa JW, Monteiro MA. Novas linguagens e novas tecnologias: educação e sociabilidade. Petrópolis, Rio de Janeiro: Vozes, 2004.

19. Jornal Contexto 2003. Jogos ajudam a desenvolver habilidades. Disponível em http://www.webartigos.com/artigos/softwa res-educativos-e-jogos-eletronicos/25059/.

20. Coscrato G, Pina JC, de Mello DF. Utilização de atividades lúdicas na educação em saúde: uma revisão integrativa da literatura. Acta Paul Enferm 2010;23(2):257-63.

21. Berenstein AM, Fernandes AA, Vilaverde PHG, Zaio TG, Vilete VG, Asenjo MN. Desenvolvimento de jogos utilizando a plataforma Unity. Rev Ceciliana 2014;5(2): 2.

22. Galán JG, Lacerda SG. Informática e telemática na educação: as tecnologias de comunicação e informação na educação. Brasília: Liber Livros,2012; p17-47.

23. Chartier, R. O mundo que se lê. Entrevista. Rev Educ 2012;16(177):11-7 Disponível em: http://revistaeducacao.uol.com.br/tex tos/177/sumario.asp.

24. Reategui EB, Moraes MC. Agentes pedagógicos animados. Novas Tecnologias na Educação 2006;4(2):1-10.

25. Marin MJS, Lima EFG, Paviotti AB, Matsuyama DT, Silva LKD, Gonzalez C, et al. Aspectos das fortalezas e fragilidades no uso das Metodologias Ativas de Aprendizagem. Rev Bras Educ Méd 2010;34(1):13-20.

26. Candeias NMF. Conceitos de educação e de promoção em saúde: mudanças individuais e mudanças organizacionais. Rev Saúde Públ 1997; 31(2):209-13.

\section{ABSTRACT \\ Gamification in oral health: experience with school of rural area}

Playing games as an additional learning strategy can bring benefits both to children, their parents, and health professionals, who may use an additional resource for achieving educational goals. This study aimed to evaluate the perceptions of countryside school children on the use of an educational software related to oral hygiene. The "Dentino" software was applied to forty-five children at a school in the rural area of the state of Rio Grande do Sul. After play, all children said they feel motivated to take care of their teeth. The application of "Dentino" received a quite satisfactory answer, providing moments of leisure and rapport among students, and acting as a teaching tool and motivation for oral health care.

Descriptors: Oral Health. Software. Dental Education.

Correspondência para:

Profa. Dra. Márcia Cançado Figueiredo

e-mail: mcf1958@gmail.com

Faculdade de Odontologia da UFRGS

Rua Ramiro Barcelos, 2492

90035-004 - Porto Alegre - RS, 